\title{
Um Estudo sobre a Utilização da Vespa Parasitoide Melittobia (Hymenoptera: Eulophidae) como Recurso Didático para o Ensino de Insetos
}

\author{
A Study On The Use Of Parasitoid Wasp Melittobia (Hymenoptera: \\ Eulophidae) As A Didactic Resource In Teaching Insects
}

\author{
Gessany da Silva Ferreira (gessany-ferreira@ hotmail.com) \\ Universidade Estadual do Sudoeste da Bahia - UESB - Campus Jequié \\ Paulo Marcelo Marini Teixeira (paulommt@hotmail.com) \\ Universidade Estadual do Sudoeste da Bahia - UESB - Campus Jequié \\ Juvenal Cordeiro Silva Junior (juvenaljr@yahoo.com.br) \\ Universidade Estadual do Sudoeste da Bahia - UESB - Campus Jequié
}

Resumo: A pesquisa salienta a importância da utilização de estratégias metodológicas inovadoras que facilitem os processos de ensino e aprendizagem. Foi desenvolvida com o objetivo analisar os limites e as possibilidades da utilização da vespa Melittobia como base para um modelo de ensino alternativo no aprendizado de tópicos relacionados aos insetos durante as aulas de Biologia destinadas para alunos do $2^{\circ}$ do ensino médio. A investigação foi realizada contando com a colaboração de 40 alunos, em projeto com duração de 9 horas/aula. A coleta de dados foi baseada em processos de observação participante, complementados pela aplicação de questionários (inicial e final) e entrevista realizada como o professor da turma de estudantes envolvidos no projeto. A análise dos dados obtidos permitiu demonstrar que a utilização da Melittobia se constitui em um recurso viável e significativo no processo de ensino-aprendizagem dos alunos.

Palavras-Chave: Melittobia; Ensino de Ciências; Insetos; inovações didáticas.

Abstract: The research highlights the importance of using methodological strategies that facilitate the teaching and learning processes, being developed with the aim of analyzing the limits and possibilities of using the Melittobia wasp as a basis for an alternative teaching model in the learning of topics related to insects during Biology classes for high school students. The investigation was carried out with the collaboration of about 40 students, in a project lasting 9 hours/ class. Data collection was based on participation observation processes, complemented by the application of questionnaires (initial and final) and an interview conducted as a teacher of the class of students involved in the project. The analysis of the obtained data showed that the use of Melittobia constitutes a viable and significant resource in the students' teachinglearning process.

Keywords: Melittobia; Science Teaching, Insects, Didactic Innovations. 


\section{INTRODUÇÃO}

A importância de um ensino de Ciências de natureza mais prática, investigativo, e com algum caráter experimental tem sido uma das pautas defendidas de forma recorrente nas discussões atuais sobre o ensino de Ciências da Natureza, especialmente dentro da área de Ensino de Biologia. Porém, ainda é predominante, no contexto educacional brasileiro, o estilo tradicional de ensino, pautado na mera transmissão de conhecimentos livrescos, num ensino excessivamente teórico e descontextualizado que pouco contribui para uma aprendizagem significativa para os educandos (KRASILCHIK, 2004; BERLEZE; ANDRADE, 2013). Além disso, há desafios relacionados à organização educacional, como falta de recursos, materiais e estrutura nas escolas, falta de preparo e de tempo para os professores desenvolverem aulas mais criativas, excesso de alunos nas classes e tantas outras situações caracterizadoras das mazelas da educação básica brasileira.

Uma das temáticas para exemplificar esse desafio é o ensino de Zoologia, mais especificamente, o ensino de tópicos relacionados ao grupo dos insetos. Este grupo apresenta ampla abundância, diversidade e importância ecológica, sendo assunto tradicionalmente tratado no currículo escolar de Biologia. Além disso, devido a essas características, os insetos se apresentam como poderosos recursos didáticos, não só no campo da Zoologia, mas também no entendimento de princípios básicos de Ecologia, Biodiversidade e Evolução. Portanto, não se trata de apenas ensinar suas características morfológicas e fisiológicas, mas incluir estudos sobre comportamento animal, desenvolvimento evolutivo, genética e interações ecológicas, suas relações com os humanos, assim como outros aspectos relevantes em relação à sustentabilidade e à preservação do meio ambiente, através de uma metodologia de ensino voltada para o educar pela pesquisa (DEMOLINER, 2005; SANTOS, 2006; MACEDO et al., 2016).

Uma das vantagens em utilizá-los como ferramentas de ensino em sala de aula é sua grande abundância na natureza. Também podem ser facilmente criados em laboratório, em atividades com baixo custo de manutenção e sem muitas restrições éticas (em comparação, por exemplo, com o estudo dos vertebrados). Ademais, o curto período de vida e os processos de mudanças físicas ao longo do seu desenvolvimento atraem a atenção dos alunos e mobiliza o interesse deles nos processos envolvidos nessas mudanças biológicas (MATTHEWS et al., 1997). 
Porém, mesmo diante das vantagens aqui apontadas, diversos estudos indicam que o grupo tem sido trabalhado de forma insatisfatória em sala de aula, sendo abordado dentro de uma perspectiva baseada apenas na memorização de conceitos e transmissão de informações descritivas, em geral com foco apenas nas características morfológicas e taxonômicas. Boa parte dos estudos desenvolvidos sobre temáticas relativas ao ensino de aspectos relativos aos insetos focalizam as concepções e representações dos estudantes e à forma como os livros didáticos tratam o assunto (SILVA et al, 2019). Outra parte busca alternativas, com o desenvolvimento de unidades de aprendizagem e recursos didáticos úteis ao ensino-aprendizagem desses conteúdos (GRUZMAN, 2003; DEMOLINER, 2005; TRINDADE et al., 2012). É dentro deste grupo que nosso estudo se enquadrou.

As vespas parasitoides do gênero Melittobia (Hymenoptera: Eulophidae) são insetos cosmopolitas, menores que $2 \mathrm{~mm}$ de comprimento que atacam, principalmente espécies de abelhas e vespas solitárias, mas também são capazes de parasitar insetos de outras ordens, incluindo imaturos de moscas (Diptera), besouros (Coleoptera) e mariposas (Lepidoptera) (MATTHEWS et al, 2009). O ciclo de vida da Melittobia é curto, durando cerca de 15 a 21 dias, dependendo das condições de criação. Após serem colocados sobre o hospedeiro, os ovos amadurecem passando pelas fases de larva, pupa e adulto. O gênero apresenta dimorfismo sexual acentuado, sendo os machos cegos e incapazes de voar. Além disso, eles passam suas curtas vidas inteiramente dentro do casulo do hospedeiro. As fêmeas são aladas, saem do ninho do hospedeiro para reiniciar o ciclo em outros locais. As Melittobia são inofensivas, não oferecendo nenhum risco a saúde humana. Estas características tornam essas vespas um material muito interessante como recurso de ensino-aprendizagem no ensino de ciências, possibilitando o desenvolvimento de aulas práticas interessantes e de forte potencial cognitivo (DAHMS, 1984; GONZÁLEZ, GERANO, MATTHEWS, 2004).

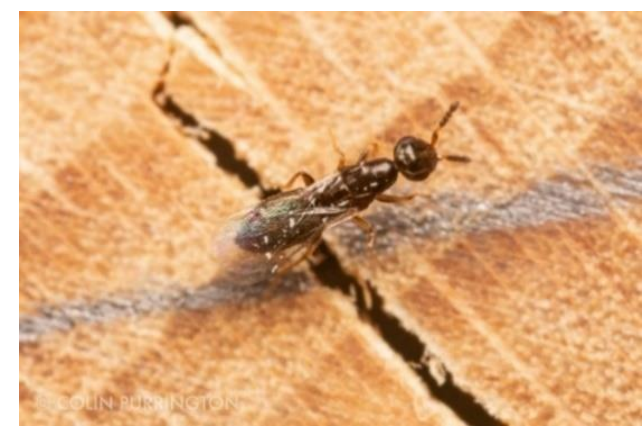

Recebido em: 05/05/2020

Aceito em: 22/09/2020 
Figura 1. Fêmea adulta de Melittobia. (Fonte: Colin Purrigton, 2018).

Nos EUA, o estudo dessas vespas faz parte do currículo de Ciências, e diversos estudos sobre a potencialidade dessa vespa como modelo alternativo de ensino em laboratórios - foram realizados por Matthews et al. (1997). No Brasil, não identificamos pesquisas e estudos com a utilização didática dessa espécie, pelo menos quando pensamos em estudos aplicados considerando o contexto da educação básica, incluindo o Ensino Fundamental e o Ensino Médio.

Diante disso, coube a seguinte pergunta sustentadora para a investigação: utilizar as vespas Melittobia como recurso didático, seria uma boa alternativa para o ensino de Zoologia, considerando o contexto educacional brasileiro? Assim, a presente pesquisa se propôs a analisar os limites e possibilidades da aplicabilidade de uma sequência didática baseada no uso de vespas parasitoides Melittobia.

\section{METODOLOGIA DA PESQUISA}

A pesquisa caracterizou-se dentro das abordagens qualitativas (LÜDKE; ANDRÉ, 2013). Foi realizada em regime de colaboração junto a 40 alunos e o professor da classe, durante as aulas regulares de Biologia de uma turma do $2^{\circ}$ ano do ensino médio, turno matutino, em um colégio público do município de Jequié/BA.

A metodologia teve caráter alinhado às modalidades de Pesquisas de Natureza Interventiva (PNI), assim caracterizadas por Teixeira e Megid Neto (2017). Trata-se de uma investigação que envolveu o planejamento, a "aplicação (execução) e análise de dados sobre o processo desenvolvido, em geral, tentando delimitar limites e possibilidades daquilo que é testado ou desenvolvido na intervenção" didática (p. 1068). Assim, o estudo teve como motivação desenvolver uma sequência didática (SD) que facilitasse o ensino de alguns tópicos sobre os insetos para os alunos, com a utilização das Melittobia, empregadas como modelos ilustrativos em atividades práticas durante as aulas. A pesquisa testou a SD em situação concreta de ensino, avaliando seus resultados em termos de ensino e aprendizagem.

Na ocasião em que propomos a aplicação da SD, o conteúdo curricular trabalhado nas aulas envolvia o estudo do Reino Animalia e seus respectivos filos. O professor de Biologia introduziu o assunto, abordando com os alunos as características gerais dos animais e as características de outros filos do referido reino. Quando a abordagem do 
professor chegou ao momento do estudo do Filo Arthropoda, as atividades dessa pesquisa foram inseridas e se iniciou o processo de intervenção didática.

Para auxiliar o desenvolvimento das atividades da SD houve o planejamento e desenvolvimento de roteiros de aula. No total, os autores produziram três roteiros: um teórico (com informações sobre a biologia e comportamento da vespa Melittobia sp.), e dois práticos, para orientar as atividades práticas em laboratório. Eles foram desenvolvidos utilizando como referência o trabalho de Mathews e Koballa (1996), e se adaptando ao planejamento curricular das aulas de Biologia e as demandas conceituais dos alunos. Antes do processo de aplicação foi realizada uma análise dos roteiros de aula e planejamento da SD de atividades propostas, na qual todo esse material passou por uma espécie da validação ${ }^{1}$ da qual participaram os orientadores do projeto e uma professora especialista da área de Zoologia.

Durante a intervenção didática, a coleta de dados se deu por meio das observações da pesquisadora que também atuou como professora durante os encontros (aulas) e a consequente produção em um diário de bordo para descrever os acontecimentos durante a intervenção. Além disso, questionários foram aplicados no início e no final do período das atividades com os alunos, com objetivo de analisar suas percepções e conhecimentos prévios sobre os insetos e potenciais aprendizagens obtidas após passarem pela SD. Também foram utilizados como dados de análise as atividades realizadas pelos alunos durante as aulas práticas propostas nos referidos roteiros. Por fim, foi realizada uma entrevista semiestruturada com o professor da turma, que auxiliou no desenvolvimento da pesquisa, com o objetivo de identificar suas percepções sobre as atividades realizadas e o grau de aplicabilidade do projeto nas aulas de Biologia da Educação Básica.

Os dados foram analisados conforme orientações de Bardin (2011), gerando material descritivo que foi objeto de leitura e análise (análise de conteúdo), redundando em quatro tópicos de discussão ou categorias de análise: 1) descrição das atividades; 2) análise dos conhecimentos prévios e percepções iniciais dos alunos envolvidos na SD; 3) análise das aulas práticas; 4) avaliação final da SD, com base nas percepções dos

\footnotetext{
${ }^{1}$ Validação aqui entendida como processo de avaliação para identificar possíveis erros conceituais e ajustes no conteúdo e na metodologia de desenvolvimento das atividades, de modo a torná-las mais adequadas para o processo de ensino e aprendizagem.
}

Recebido em: 05/05/2020

Aceito em: 22/09/2020 
alunos e do professor de Biologia. Finalizamos a análise identificando limites e possibilidades da utilização da SD e das vespas Melittobia sp. como recurso nas aulas de Biologia.

\section{RESULTADOS E DISCUSSÕES}

\section{1 - DESCRIÇÃO DA SEQUÊNCIA DIDÁTICA}

O período de aplicação do projeto compreendeu um total de cinco encontros, sendo que cada encontro composto por duas aulas de 50 minutos, totalizando, aproximadamente 9 horas/aula, conforme ilustramos no Quadro 1.

Quadro 1 - Organização das aulas da sequência didática.

\begin{tabular}{|c|c|}
\hline $\begin{array}{c}\mathrm{N}^{\mathbf{o}} \mathrm{de} \\
\text { encontros }\end{array}$ & Descrição das Atividades \\
\hline 1 & $\begin{array}{l}\text { - Apresentação da proposta de atividade para os alunos; } \\
\text { - Momento de observação das aulas; }\end{array}$ \\
\hline 2 & Coparticipação em aula - observações sobre a turma e as aulas; \\
\hline 3 & $\begin{array}{l}\text { Início da aplicação da sequência didática (parte teórica): } \\
\text { - Aula expositiva participada: Filo Arthropoda e Classe Insecta: características } \\
\text { gerais. } \\
\text { - Aplicação do questionário inicial para coleta de dados: identificando as } \\
\text { concepções dos estudantes; } \\
\text { - Apresentação da vespa Melittobia sp. como inseto-modelo; } \\
\text { - Entrega do Roteiro Teórico; }\end{array}$ \\
\hline $\begin{array}{r}\mathbf{4} L \\
\end{array}$ & $\begin{array}{l}\text { Aula prática em laboratório: } \\
\text { - Estudo da anatomia e morfologia dos insetos utilizando modelos vivos de vespas } \\
\text { Melittobia sp.; }\end{array}$ \\
\hline 5 & $\begin{array}{l}\text { Aula prática em laboratório: } \\
\text { - Análise dos hábitos parasitoides e observação do ciclo de vida da Melittobia sp.; } \\
\text { - Aplicação do questionário final para coleta de dados; avaliação do projeto. }\end{array}$ \\
\hline
\end{tabular}

Nos dois primeiros encontros foram realizadas observações pela pesquisadora durante as aulas e momentos de coparticipação com o professor de Biologia, com o objetivo de criar mais afinidade com os alunos e captar melhor o enfoque dado pelo professor aos conteúdos de Zoologia, para que as atividades da pesquisa se adaptassem mais adequadamente às demandas de aprendizagem dos alunos.

No $3^{\circ}$ encontro foi realizada uma aula expositiva participada, sob responsabilidade da pesquisadora, abordando a riqueza, diversidade, importância ecológica e as principais características do Filo Arthropoda, culminando no grupo taxonômico que 
seria o foco do estudo: a classe Insecta. A introdução aos artrópodes teve como objetivo contextualizar para os alunos detalhes sobre a posição filogenética e taxonômica desse grupo em relação a outros grupos de animais.

Após essa introdução, foi dado enfoque para a classe Insecta. Porém, antes de prosseguir com o tema, um questionário do tipo pré-teste foi aplicado junto aos alunos, com objetivo diagnosticar seus conhecimentos prévios sobre o assunto. A seguir, houve a discussão sobre aspectos da diversidade, importância, riqueza dos insetos, características morfológicas e modos de reprodução, com ênfase no grupo das vespas parasitoides (Hymenoptera: Parasitica), da qual a vespa Melittobia sp. faz parte. Por fim, o primeiro roteiro teórico foi entregue para os estudantes, com informações prévias sobre a vespa Melittobia sp. Adicionalmente, esse encontro teve como objetivo avaliar os conhecimentos prévios dos alunos sobre o assunto, bem como desconstruir algumas possíveis noções errôneas/equivocadas que os mesmos poderiam sustentar sobre o grupo dos insetos para que, posteriormente, as aulas práticas fossem mais proveitosas.

A partir do $4^{\circ}$ e $5^{\circ}$ encontros as atividades práticas aconteceram no laboratório do colégio. Os materiais utilizados nas aulas foram cedidos gentilmente pela Universidade Estadual do Sudoeste da Bahia (UESB - Campus Jequié), e consistiram de seis lupas, pincéis finos, lâminas de vidro, glicerina e frascos com as vespas Melittobia sp. fixadas em álcool e indivíduos vivos. As vespas Melittobia sp. foram obtidas por meio de uma criação mantida no Laboratório de Biologia de Insetos (LaBI).

As duas aulas em laboratório aconteceram sob responsabilidade da pesquisadora, com o auxílio do professor de Biologia. Como a turma participante da intervenção era composta por 40 alunos, foi necessário realizar a divisão dos alunos em dois grupos de 20 estudantes, de modo que a aula pudesse ser mais eficiente e todos pudessem participar nas observações e atividades realizadas. Dessa forma, como as aulas de Biologia aconteciam em horários duplos, a turma se dividiu em dois grupos que se intercalavam entre realizar as atividades em laboratório com a pesquisadora, enquanto o outro grupo permanecia em sala de aula com o professor, desenvolvendo o planejamento normal das aulas. Durante as aulas em laboratório, os alunos foram divididos em pequenos grupos para que pudessem observar utilizando a lupa e discutir entre si o que estavam vendo e resolver os questionamentos propostos nos roteiros entregues no início da atividade.

Recebido em: 05/05/2020

Aceito em: 22/09/2020 
$\mathrm{O} 4^{\circ}$ encontro teve como objetivo trabalhar as principais características morfológicas dos insetos, bem como, apresentar a vespa Melittobia sp. aos alunos. No $5^{\circ}$ encontro os alunos observaram o ciclo de vida dos insetos e conheceram em detalhes os hábitos parasitoides da vespa. Roteiros práticos foram entregues aos alunos com atividades que nortearam o desenvolvimento das aulas em laboratório. No final das atividades, para encerrar a SD, um questionário final foi aplicado aos alunos com o objetivo de coletar dados sobre potenciais efeitos da intervenção sobre as percepções e conhecimentos dos alunos do grupo estudado.

\section{2 - ANALISANDO OS CONHECIMENTOS PRÉVIOS DOS ALUNOS:}

Por meio do questionário inicial aplicado no terceiro encontro foi possível identificar os conhecimentos prévios que os alunos sustentavam sobre os "insetos". Dessa forma, poderíamos desenvolver as atividades da SD com base em suas percepções, tentando problematizá-las. Segundo Bovo (2004), quando se ensina, é necessário considerar as dimensões de aprendizagem dos alunos - como eles compreendem o mundo ao seu redor. Ou seja, o professor precisa levar em consideração os conhecimentos prévios de seus alunos durante o processo de ensino-aprendizagem, podendo, assim, intervir, ampliando e facilitando o processo de aprendizagem dos estudantes.

Duas questões principais nortearam a análise dos conhecimentos prévios. $\mathrm{Na}$ primeira os alunos foram questionados sobre o que eles sabiam sobre os insetos. Alguns alunos buscaram construir suas respostas com base no que tinha sido discutido anteriormente sobre o Filo Arthropoda ( $\cong 57 \%$ dos alunos) e o restante basearam suas ideias em percepções e sentimentos pessoais sobre os insetos.

\footnotetext{
"Os insetos são seres artrópodes, que na maioria das vezes possuem semelhanças entre si, mas são bastante diversificados e muito presentes no nosso cotidiano, têm um papel crucial nos ecossistemas" - Aluno A.

Os insetos muitas das vezes causam medo, pânico e nojo nas pessoas, eu por exemplo sinto muita raiva da mosca e do pernilongo. Não tenho medo, porém alguns deles são bem chatinhos. Um inseto que prende muito a minha atenção e eleva o meu pensamento é a borboleta" - Aluna B
}

As respostas oferecidas pelos alunos demonstram que os recursos visuais (slides em powerpoint) e as discussões levantadas durante a aula teórica ajudaram eles a relacionarem os insetos a um grupo taxonômico mais abrangente e fixar algumas informações importantes sobre os insetos. Foi possível notar também que para boa parte 
dos estudantes os insetos evocam emoções e sentimentos, sendo em maioria sentimentos e ideias negativas.

Na segunda parte do questionário eles foram convidados a escrever três palavras para expressar suas percepções e sentimentos quando ouviam falar algo sobre "insetos". O objetivo deste momento foi aplicar a técnica de associação livre de palavras, descrita por Bardin (2011) como um método utilizado para fazer surgir espontaneamente associações relativas a um determinado tema trabalhado. Com as palavras obtidas no questionário foi produzida uma nuvem de palavras (Figura 2) para ilustrar, de forma geral, os principais adjetivos, substantivos e verbos utilizados pelos alunos para descrever o grupo dos insetos, segundo suas percepções naquele momento.

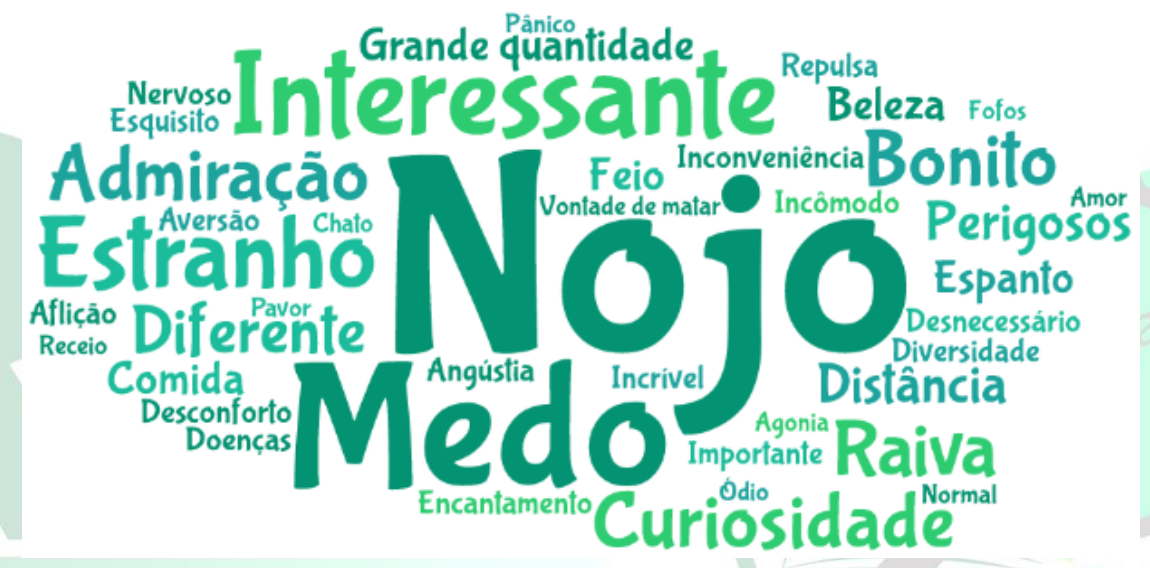

Figura 2: Nuvem de palavras com ideias citadas pelos alunos para representar suas percepções e sentimentos sobre os insetos.

No total, nesta atividade, foram obtidas 89 palavras que após classificação, foram organizadas em ordem de maior para a menor frequência, sendo que aquelas com maior tamanho na nuvem representam as percepções mais frequentes entre os alunos. Os resultados foram bem semelhantes a categoria de respostas pessoais oferecidas pelos alunos na questão anterior. Ao observar a nuvem é possível identificar que as duas palavras mais frequentes foram: nojo e medo, representando $47 \%$ do total de palavras apontadas pelos alunos. Segundo Costa-Neto e Pacheco (2004), essa tendência à visão negativa é algo enraizado no contexto cultural, isto é, são representações construídas socialmente. Dessa forma, é comum que os alunos cheguem à sala de aula com ideias errôneas pré-estabelecidas, sendo papel da escola e, particularmente do professor de Biologia, problematizar essas visões, ajudando-os a construir uma visão mais crítica e amparada nos conhecimentos científicos. 
Entretanto, apesar da maioria das palavras utilizadas terem conotação negativa, os alunos também citaram palavras que representavam sentimentos e percepções positivas como: "interessante", "admiração", "beleza", "curiosidade", dentre outras. Isso demonstra que, apesar da forte perspectiva pejorativa, os insetos também despertam o interesse e a curiosidade dos estudantes.

Análises iniciais como a aqui desenvolvida, ajudam os professores a planejar e desenvolver atividades direcionadas, para incentivar os alunos a construírem um olhar mais crítico, problematizando suas perspectivas e incentivando-os a romper com conceitos errôneos e equivocados que possam ser evidenciados durante as aulas (CONTENTE, 2017).

\section{3 - ANALISANDO AS ATIVIDADES PRÁTICAS:}

A seguir, discutiremos resultados obtidos durante as aulas desenvolvidas em laboratório que foram realizadas a partir do quarto encontro.

Inicialmente, os alunos foram orientados a formar grupos de três a quatro pessoas, aproximadamente. Cada grupo ficou responsável por uma lupa de aumento, contendo uma lâmina com cinco vespas fixadas em álcool e mergulhadas em glicerina bidestilada, sendo quatro fêmeas e apenas um macho (Figura 3). As lâminas foram organizadas dessa forma para que os estudantes pudessem visualizar, na prática, o dimorfismo sexual característico da espécie.

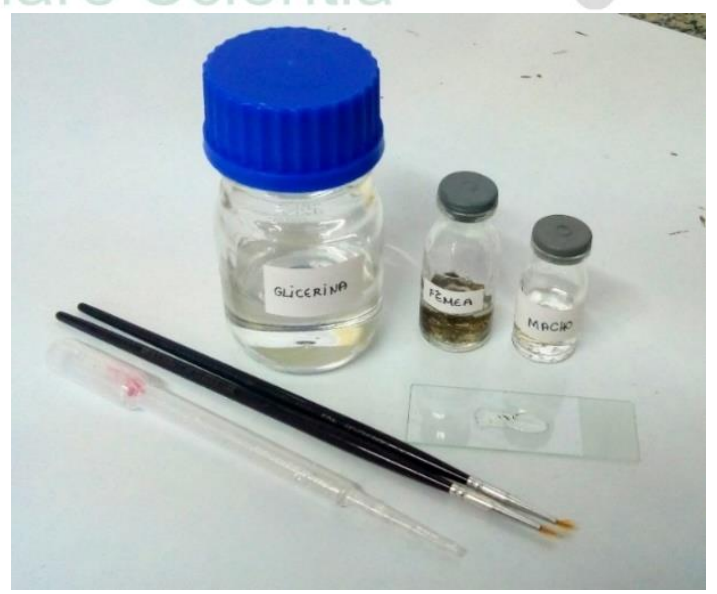

Figura 3. Materiais utilizados durante as atividades práticas no quarto encontro: glicerina, vespas Melittobia fêmeas e machos fixadas em álcool, pincéis, pipetas, lâminas, e lupas de aumento.

No decorrer da aula a pesquisadora buscou não oferecer respostas prontas para os alunos, incentivando-os a explorar o roteiro teórico (entregue na aula teórica anterior) 
em busca de informações que pudessem auxiliá-los em suas dúvidas e resoluções, adotando a postura de mediadora nas discussões.

A primeira atividade consistiu na técnica do "desenho orientado", descrito por Mathews et al. (1996). Os alunos foram orientados a observar atentamente a morfologia externa das vespas presentes na lâmina e depois representar, por meio de um desenho esquemático, todos os detalhes que conseguissem captar. Além disso, deveriam indicar as principais características presentes nos espécimes, como cabeça, tórax, abdômen, pernas, asas, antenas e olhos. Em seguida, foi solicitado que os alunos buscassem identificar o macho e a fêmea nas lâminas. A maioria dos alunos respondeu corretamente, identificando corretamente as fêmeas e os machos, citando inclusive as principais diferenças encontradas nos machos, como: coloração mais amarelada, asas menores (comparadas às da fêmea), antena com estrutura mais desenvolvida, dentre outras características mencionadas na parte teórica da SD (ver Figura 4).
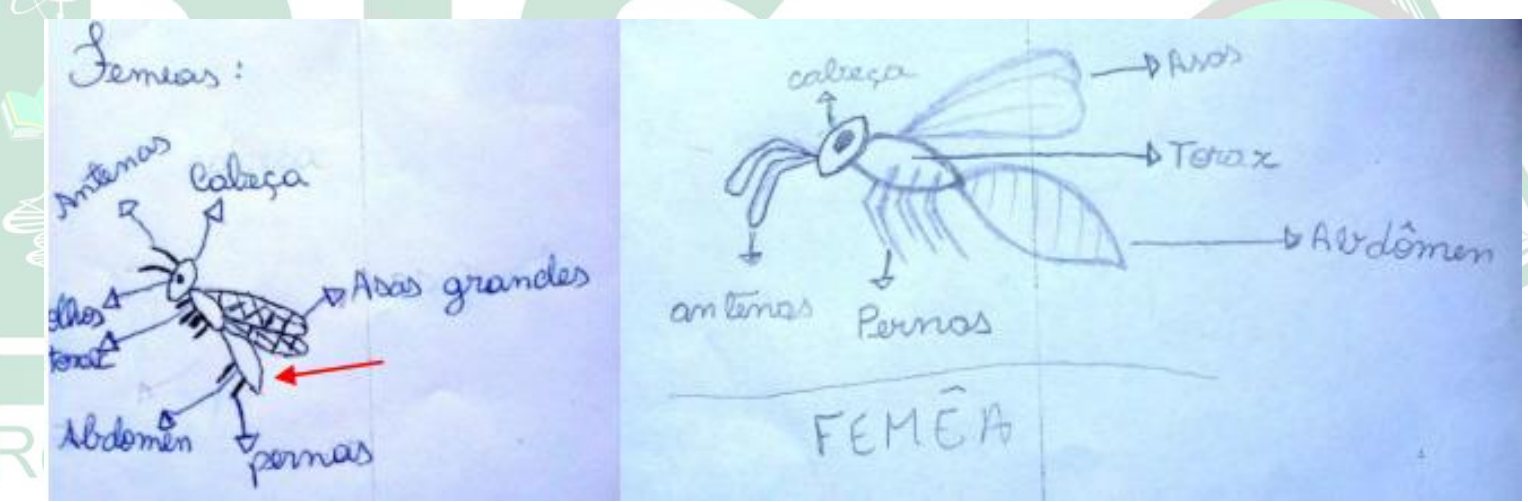

Figura 4. Desenhos esquemáticos da vespa Melittobia realizados pelos alunos durante a aula em laboratório, representando as características morfológicas dos insetos.

Ao iniciar a atividade, os alunos passaram bastante tempo observando as vespas nas lupas, demonstrando surpresa e curiosidade com relação a cada detalhe que percebiam, interagindo e propondo várias perguntas sobre o que observavam. Durante a realização da atividade muitos apresentaram dúvidas sobre a localização do tórax e abdômen das vespas, porém durante as discussões entre o grupo, com o auxílio do roteiro teórico e das orientações apresentadas, eles conseguiram sanar suas dúvidas. Analisando as atividades realizadas, foi possível identificar que a maioria dos grupos conseguiu desenvolver a atividade, identificando corretamente as principais características morfológicas dos insetos em foco no trabalho realizado. 
No $5^{\circ}$ e último encontro, discutimos algumas informações com enfoque ecológico.

A atividade foi dividida em dois momentos. Inicialmente, foi realizada pela professorapesquisadora uma explanação teórica sobre os hábitos parasitoides da vespa Melittobia e suas relações com seus hospedeiros, a vespa social - Polistes canadensis (Hymenoptera: Vespidae), também conhecida por marimbondo vermelho (Figura 5). O ninho e diferentes estágios de desenvolvimento dos marimbondos foram disponibilizados para que os alunos observassem na lupa. $\mathrm{Na} 1^{\mathrm{a}}$ atividade, os alunos deveriam anotar no roteiro algumas informações importantes que foram explicadas, como: o nome científico do hospedeiro e qual a fase larval ideal para deposição dos ovos e duração do ciclo de vida da Melittobia.
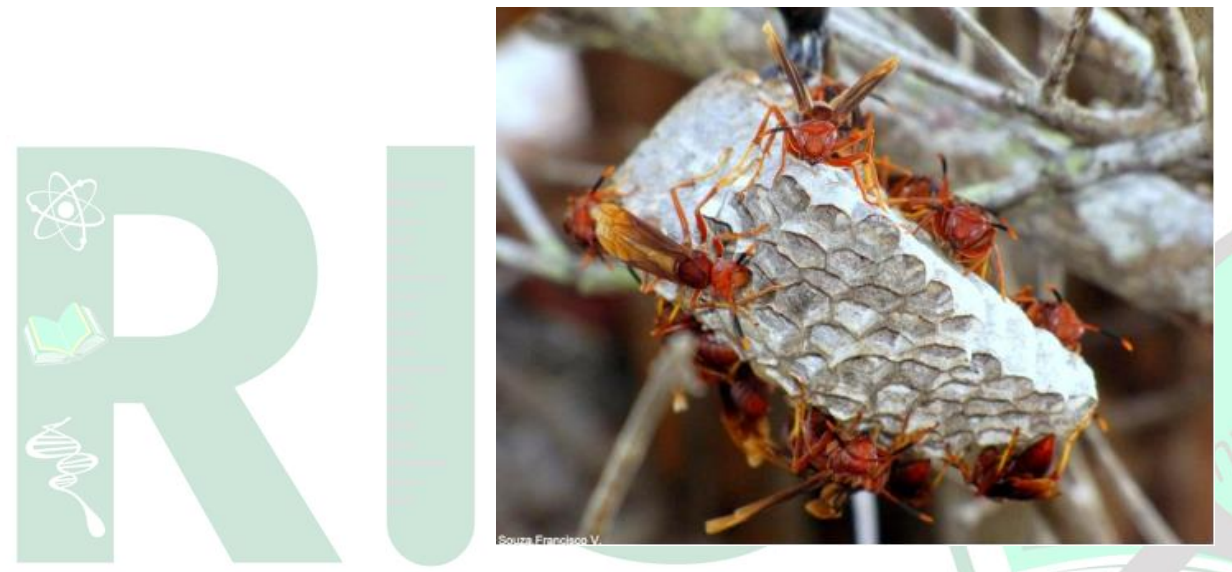

Figura 5. Vespa Polistes canadensis, popularmente conhecida por marimbondo vermelho, utilizada durante a aula prática como hospedeiro da vespa Melittobia. Fonte: Souza Francisco V.

Durante a realização das atividades, os alunos puderam participar livremente, demonstrando interesse, além de contribuírem por meio de questionamentos e relatos de suas experiências e percepções - por vezes, negativas - sobre os marimbondos, possibilitando o desenvolvimento de várias discussões sobre a diversidade e a importância ecológica desses insetos e sobre o papel das vespas nos ecossistemas. Os marimbondos vermelhos são vespas comuns na região onde a pesquisa foi realizada e a utilização dessas vespas os ajudou a associar com o estudo da vespa Melittobia, até então desconhecida, contribuindo para que os alunos pudessem aplicar no dia a dia o conhecimento obtido em sala de aula.

No $2^{\circ}$ momento da aula, quatro lupas foram organizadas e enumeradas, de sorte que cada uma delas apresentava fases distintas do ciclo de vida da Melittobia (ovo, pupa, larva e adultos). Na atividade os alunos teriam que observar os estágios de desenvolvimento presente no frasco. As duas primeiras lupas tinham frascos com Recebido em: 05/05/2020 
Vol. 3, n. 5. Set./Dez.

ISSN: 2595- 4520

vespas adultas e larvas do hospedeiro no processo inicial de parasitismo, ou seja, com a presença de ovos e larvas de Melittobia sobre o hospedeiro. As outras lupas continham lâminas com pupas e adultos de Melittobia, respectivamente (Figura 4).
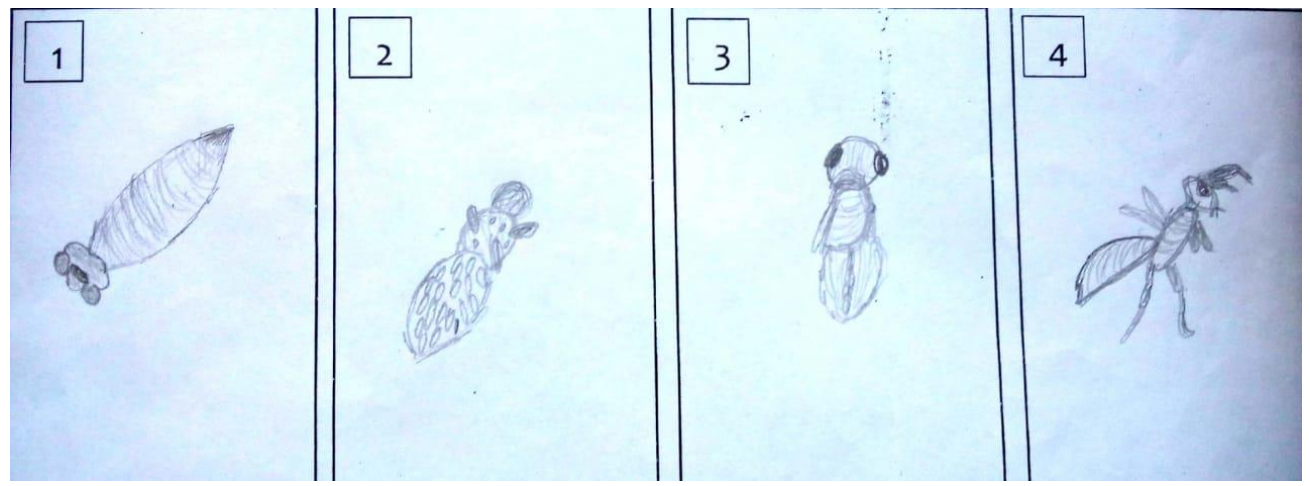

Figura 6. Atividade realizada pelos alunos representando os diferentes ciclos de vida da vespa observados na lupa.

Todos os alunos observaram as fases presentes nas lupas, pois à medida que um grupo observava a lupa, trocava de lugar com outro que ainda não tinha observado. Assim, todos os alunos conseguiram concluir a atividade proposta e visualizar os diferentes ciclos de vida dos insetos, representando suas observações por meio de desenhos.

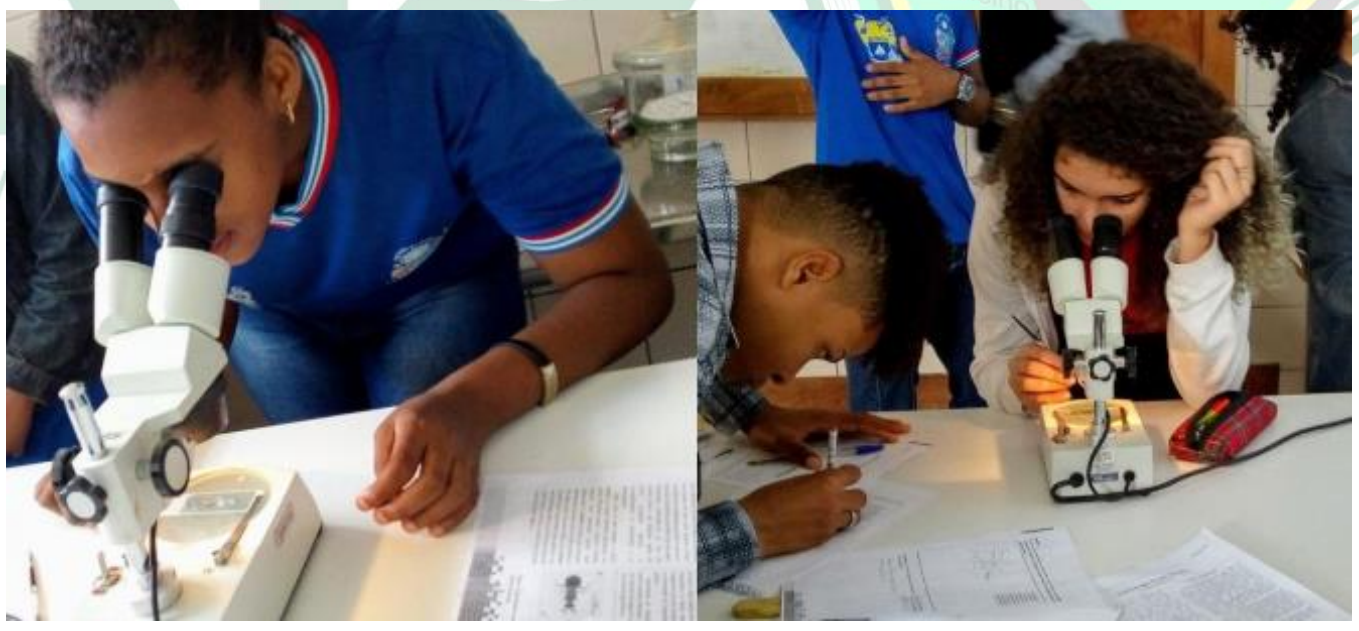

Figura 7. Alunos durante a realização das atividades no laboratório.

\section{4 - AVALIANDO A INTERVENÇÃO}

Para avaliar o impacto e a aplicabilidade da intervenção foi aplicado um questionário final com os alunos e uma entrevista semiestruturada com o professor de Biologia.

Recebido em: 05/05/2020

Aceito em: 22/09/2020 
Inicialmente os alunos responderam questões em que avaliavam a SD e em outra parte do questionário as questões estavam relacionadas ao conhecimento obtido pelos alunos sobre os insetos e suas atuais percepções - após a intervenção.

Quando perguntados sobre as aulas que aconteceram no laboratório, 96\% dos alunos disseram gostar muito; 93\% dos alunos afirmaram que o uso da vespa Melittobia auxiliou no estudo e na compreensão do grupo dos insetos. Algumas das respostas e justificativas dos alunos foram as seguintes:

\footnotetext{
"Sim, porque ver as estruturas reais no microscópio ajuda a compreender melhor o conteúdo, ou seja, o contato mais próximo com aquilo que é passado, permite um melhor entendimento" - Aluna L.

"Sim, porque [a Melittobia] é um inseto que tem suas fases bem desenvolvidas, e bem mais fácil seu entendimento" - Aluna V.
}

Assim, percebemos as atividades práticas como uma "fonte de maiores esclarecimentos e dúvidas tornando as aulas teóricas mais fáceis de compreender e mais diversificadas" (SANTOS, 2014, p. 35).

Os alunos também foram questionados sobre como explicariam para alguém o que é um "inseto". Essa questão foi bem semelhante ao que foi feito no questionário inicial, e teve como objetivo de realizar uma comparação entre o conhecimento e as percepções dos alunos sobre os insetos antes e depois da intervenção (SD), identificando se os objetivos propostos para o projeto foram alcançados. A maioria dos alunos respondeu com informações mais estruturadas do que as respostas fornecidas no questionário inicial. Alguns alunos responderam descrevendo as características morfológicas (três pares de pernas, fases de desenvolvimento, presença de exoesqueleto) e informações sobre a classificação taxonômica (filo Arthopoda, Hexapoda etc.). Muitos alunos também citaram informações sobre a importância ecológica e biológica, como a abundância e diversidade do grupo e o impacto deles na natureza.

Em seguida, perguntamos sobre o papel dos insetos no Planeta. Os alunos citaram o papel na agricultura (controle biológico realizado pelos parasitoides), o papel na polinização e a importância na saúde. Grande parte deles também citou o papel dos insetos no equilíbrio dos ecossistemas e a importância desse grupo nas cadeias alimentares, como decompositores de alimentos.

Por fim, assim como no questionário inicial, os alunos foram convidados a escrever palavras que definissem suas percepções e sentimentos sobre os insetos. Foram 
obtidas um total de 77 palavras, que após análise foram organizadas em ordem de maior para menor frequência, resultando em uma nuvem de palavras (Figura 5).

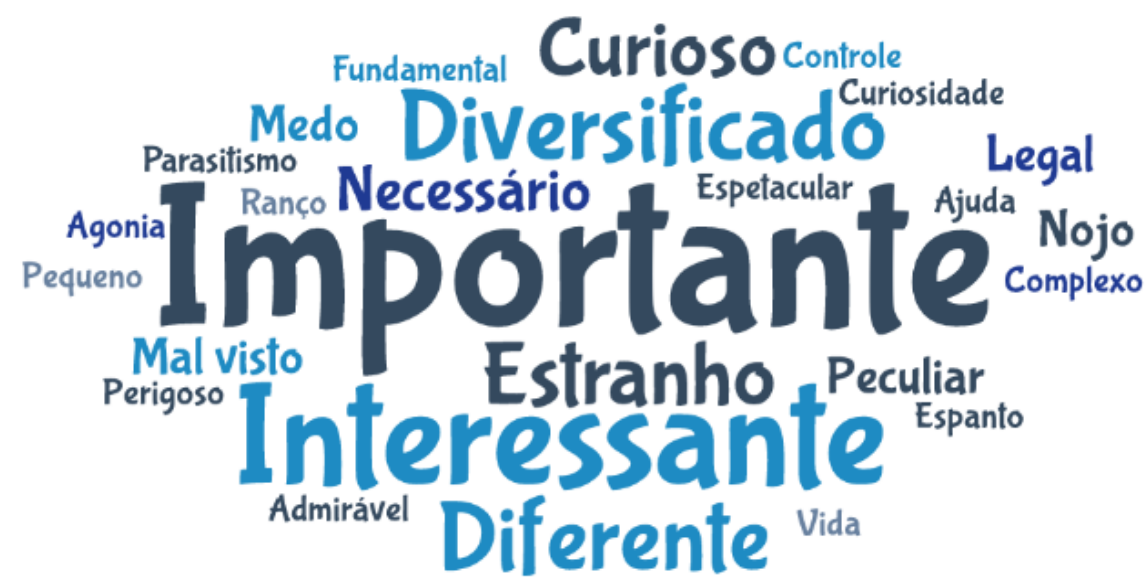

Figura 8. Nuvem de palavras citadas pelos alunos no questionário final, sobre as percepções e sentimentos sobre os insetos.

Observando a nuvem foi possível identificar que as palavras mais frequentes foram: "importante" e "interessante", correspondendo a cerca de $32 \%$ das palavras citadas. Essas palavras também foram mencionadas pelos alunos no questionário inicial, mas, naquele momento, em menor frequência. Ao contrário da nuvem do questionário inicial, percebe-se que o número de palavras que representam percepções positivas é muito maior do que aquelas que representam as percepções negativas, demonstrando que as discussões e a ação interventiva contribuíram para a mudança de perspectiva de grande parte dos alunos. Algumas palavras citadas fazem menção à experiência Melittobia sp., como "parasitismo", “controle [biológico]”, "pequeno". Palavras negativas ainda foram mencionadas, mas percebe-se que após a intervenção os alunos assumiram atitudes menos depreciativas - palavras como "peculiar", "complexo", "mal visto", exemplificam essa mudança de perspectiva.

Já na entrevista, o professor destacou a importância inovações didáticas durante as aulas de Biologia, citando a sequência didática realizada como uma experiência positiva no processo de ensino aprendizagem dos alunos participantes,

\footnotetext{
"Quando a gente apresenta para o aluno a anatomia do indivíduo, ele consegue compreender melhor como é que essas estruturas se articulam - como funcionam na prática. Acredito que se torna mais palpável e faça mais sentido para eles. [...] No geral, ele consegue entender, basicamente como é que funciona. [...] Para eles é extremamente incentivador e empolgante. [...] Pude
} 
perceber que houve uma diferença gigantesca na visão que eles possuíam sobre os insetos" (PROFESSOR DA TURMA).

Porém, ele também citou a possibilidade de utilização de outros grupos de insetos ou artrópodes mais acessíveis no dia a dia dos alunos, para desenvolver aulas práticas com resultados semelhantes. Em relação aos roteiros propostos para orientar as aulas, o professor avaliou como um material que auxiliou no desenvolvimento das atividades.

Foram discutidos também alguns desafios encontrados durante a aplicação das atividades em laboratório, como por exemplo, o curto período durante aulas e a grande quantidade de alunos por sala, o que, em condição normal de aula, isto é, sem o auxílio da pesquisadora, tornaria a aplicação da SD mais desafiante. De forma geral, ele concluiu que a SD conseguiu alcançar os objetivos propostos, se configurando como uma alternativa interessante para o processo de ensino aprendizagem dos alunos.

\section{CONSIDERAÇÕES FINAIS}

Com base nos resultados obtidos, verificamos que a intervenção foi uma experiência avaliada como positiva pelos alunos, auxiliando-os a ampliar suas visões sobre o grupo dos insetos estudados e aprofundar conhecimentos sobre esses seres vivos, bem como, sobre sua importância no meio ambiente. Também constatamos que ao final da intervenção, grande parte dos alunos relataram mudança nas percepções predominantemente negativas sobre os insetos, passando a apresentar expressões de natureza apreciativa pelo grupo.

As vantagens da utilização de SD dessa natureza estão na articulação de elementos teóricos e práticos, com o desenvolvimento de atividades práticas no laboratório da escola, proporcionando aos estudantes observações, pequenas experimentações e discussões sobre o assunto estudado. Além do mais, o conteúdo relacionado aos insetos não se ateve somente às suas características taxonômicas e ao estudo descritivo de elementos morfo-fisiológicos.

Também foram identificados limites na aplicação da sequência de atividades. Alguns deles foram relacionados à organização escolar, como o curto período disponível para as aulas e para a realização das atividades, e a grande quantidade de alunos da sala, dificultando um trabalho mais pormenorizado com cada grupo de alunos. Existe também o limite relacionado à criação e manutenção das vespas para sua utilização didática.

Recebido em: 05/05/2020

Aceito em: $22 / 09 / 2020$ 
Reconhecemos que diante das limitações encontradas na estrutura das escolas, como a falta de materiais, laboratórios e de preparo para o desenvolvimento das práticas, a preparação das aulas pode gerar obstáculos para o professor de Ciências. Por isso, destacamos a necessidade de projetos que estabeleçam pontes entre a universidade e os professores da educação básica, garantindo aos professores preparo de alguns materiais e espécimes para o desenvolvimento dessas atividades. Assim, inovações passam a ser mais acessíveis aos professores, desafiando-os a repensar suas práticas e metodologias utilizadas em sala de aula.

Apesar dos desafios existentes, salientamos a importância da busca de metodologias e recursos visando a melhoria da qualidade da educação científica nas escolas, sendo a utilização de vespas Melittobia uma das estratégias aqui defendidas para aplicação durante as aulas de Biologia. Para isso, serão necessárias a realização de estudos complementares com essas vespas, com o objetivo de promovê-las e divulgá-las como um organismo - modelo significativo para o ensino de Ciências, dado que no Brasil não há outros registros de estudos realizados sobre tais vespas utilizadas como ferramenta de ensino.

\section{REFERÊNCIAS}

BARDIN, L. (Org.). Análise de conteúdo. São Paulo/SP: Edições 70, 2011.

BERLEZE, J. E.; ANDRADE, M. A. B. O uso de aulas práticas no ensino da biologia. In. Desafios da escola pública paranaense na perspectiva do professor PDE, 2013.

BOVO, M. C. Interdisciplinaridade e transversalidade como dimensão da ação pedagógica. Revista Urutágua (Online), v. 7, p. 1-12, 2004.

CONTENTE, M. P.; MACHADO, C. R. S.; SOUSA, E. S.; MACHADO, C. R. S. O ensino de Artrópodes mediado por uma sequência de ensino investigativa. In: Encontro Nacional de Pesquisa em Educação em Ciências, 2017, Florianópolis: ABRAPEC, 2017. v. 11. p. 1-10.

COSTA-NETO, E. M. C.; PACHECO, J. M. A construção do domínio etnozoológico "inseto" pelos moradores do povoado de Pedra Branca, Santa Terezinha, Estado da Bahia. Acta Scientiarum. Biological Sciences. 26 (1): 81-90, 2004.

DAHMS, E.C. Revision of the genus Melittobia (Chalcidoidea: Eulophidae) with the description of seven new species. Mem. Queensland Mus. 21: 271-336, 1984.

DEMOLINER, M. S. Unidade de aprendizagem sobre insetos: avaliando uma proposta metodológica para o ensino fundamental. Faculdade de Física, Pontifícia 
Universidade Católica - RS. Dissertação de Mestrado - Educação em Ciências e Matemática. Porto Alegre/RS, 2005.

GONZÁlEZ J.M; GENARO, J.A; MATTHEWS, R.W. Species of Melittobia (Hymenoptera: Eulophidae) established in Bahamas, Costa Rica, Cuba, Hispaniola, Puerto Rico, and Trinidad. Florida Entomologist. 87: 619-620, 2004.

GRUZMAN, E. Representações dos insetos através da imagem: uma investigação teórico-prática para a realização de um vídeo educativo em ecoentomologia. Dissertação (Mestrado)- Universidade Federal do Rio de Janeiro, Rio de Janeiro, 2003.

KRASILCHIK, M. Prática de Ensino de Biologia. São Paulo/SP: Editora da Universidade de São Paulo, 2004.

LIMA, R. L. Uma proposta de ensino para o nível fundamental a partir das concepções sobre insetos. 2012. 97f. Dissertação de Mestrado (Ensino de Ciências Naturais e Matemática) - Centro de Ciências Exatas e da Terra, Universidade Federal do Rio Grande do Norte. Natal/RN, 2012.

LÜDKE, M.; ANDRÉ, M. E. D. A. Pesquisa em educação: abordagens qualitativas. Rio de Janeiro/RJ: EPU, 2013.

MACEDO, M.V. et al. Ensinar e aprender Ciências e Biologia com os insetos. In: Da-Silva, E.R.; Passos, M.I.S.; Aguiar, V.M.; Lessa, C.S.S. \& Coelho, L.B.N. (eds.) Anais do III Simpósio de Entomologia do Rio de Janeiro. Universidade Federal do Estado do Rio de Janeiro (UNIRIO), Rio de Janeiro, p. 12-23. 2016.

MATTHEWS, R. W; FLAGE, L. R.; MATTHEWS, J. R. Insects as teaching tools in primary and secondary education. Annual Review of Entomology. v. 42, p. 269-289, 1997.

MATTHEWS, R. W; J.M. GONZÁLEZ; J.R. MATTHEWS; L.D. Biology of the parasitoid Melittobia (Hymenoptera: Eulophidae)". Annual Review of Entomology. 54: 251-266. doi:10.1146/annurev.ento.54.110807.090440. 2009.

MATTHEWS, R. W., T. R; KOBALLA Jr., L. R; FLAGE, E. J. Pyle. WOWBugs: New Life for Life Science. Riverview Press, Athens, GA. 318 pp. 1996.

MODRO, A. F. H. et al. Percepção entomológica por docentes e discentes do município de Santa Cruz do Xingu, MT, Brasil. Biotemas, v. 22, n. 2, p. 153-159, 2009

PESSOA, V. A.; ARAÚJO, M. L. F. O uso da experimentação nas aulas de Ciências e Biologia na escola pública. In: Jornada de ensino, pesquisa e extensão - JEPEX, 9,2009, Recife/PE. Anais (on-line). Recife/PE: UFRPE, 2009.

SANTOS, A. R. Antenas ligadas para preservar a biodiversidade: concepções alternativas no ensino de Ciências. Instituto Oswaldo Cruz, Fundação Oswaldo Cruz. Dissertação de Mestrado - Ensino em Biociências e Saúde. Rio de Janeiro/RJ, 2006. 
SANTOS, K. P. A importância de experimentos para ensinar ciências no enino fundamental. 2014. Monografia (Especialização em Ensino de Ciências) Universidade Tecnológica Federal do Paraná, Medianeira.

SILVA, B.; SILVA, R.; FRÓES, M. Novas percepções conquistadas por alunos do ensino integral da escola Felipe dos Santos no Município de Inconfidentes-MG sobre alguns artrópodes por meio da educação ambiental. Revista Insignare Scientia - RIS, v. 2, n. 1, p. 91-103, 20 maio 2019.

TEIXEIRA, P. M. M.; MEGID NETO, J. Uma proposta de tipologia para Pesquisas de Natureza Interventiva. Ciência \& Educação, v. 23, n. 4, p. 1055-1076, 2017.

TRINDADE, O. S. N.; SILVA JUNIOR, J. C.; TEIXEIRA, P. M. M. Um estudo das representações sociais de estudantes do ensino médio sobre os insetos. Ensaio. Pesquisa em Educação em Ciências, v. 14, n.3, p. 37-50, 2012.

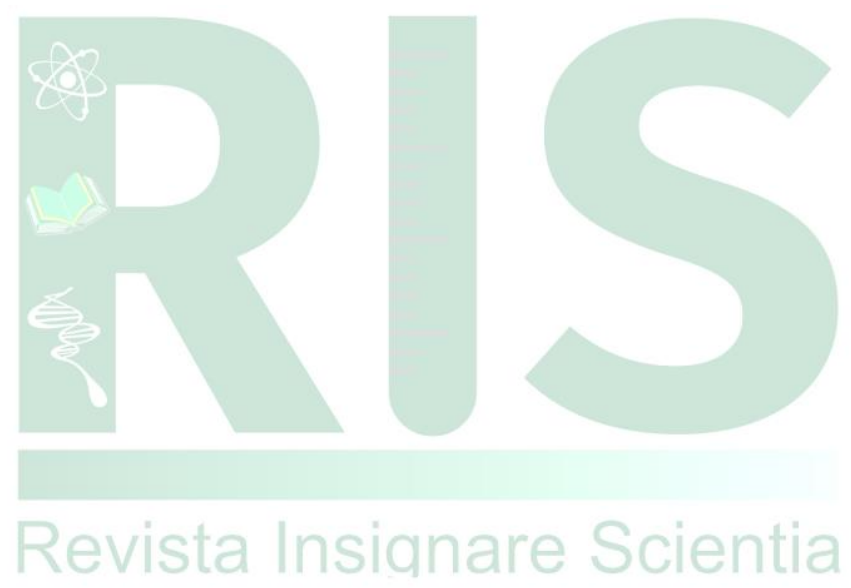

